JSAI : Journal Scientific and Applied Informatics

Vol. 4, No. 3, November 2021, hal. 280 285

E-ISSN: 2614-3054; P-ISSN: 2614-3062, Terakreditasi Kemenristekdikti, Sinta 5

\title{
E-LEARNING MATA PELAJARAN SIMULASI DIGITAL PADA SEKOLAH MENENGAH KEJURUAN NEGERI 3 KOTA GORONTALO
}

\author{
${ }^{1}$ Hariati Husain, ${ }^{2}$ Citra Yustitya Gobel, ${ }^{3}$ Zufriato K. Dunggio, \\ ${ }^{1,2}$ Universitas Ichsan Gorontalo, Indonesia \\ ${ }^{3}$ STMIK Ichsan Gorontalo, Indonesia \\ Ihariatihusain1405@gmail.com; '2gobelcitra87@gmail.com,zufry2dunggio@gmail.com
}

\begin{tabular}{l} 
Article Info \\
\hline Article history: \\
Received, 30/08/2021 \\
Revised, 07/09/2021 \\
Accepted, 13/11/2021 \\
\end{tabular}

\section{Kata Kunci:}

Simulasi Digital

e-learning

Webiste

\begin{abstract}
ABSTRAK
Mata Pelajaran Simulasi Digital sebagai salah satu mata pelajaran yang dipelajari di SMK Negeri 3 Gorontalo pada kurikulum 2013. Simulasi Digital merupakan Mata Pelajaran pada jurusan TKJ, Desain Permodelan dan Informasi Bangunan dan dan Jurusan Bisnis Konstruksi dan Properti [1]. Dalam Penelitian ini di rumuskan permasalahan yang terjadi adalah terbatasnya waktu membuat guru sulit untuk menyampaikan dan melaksanakan pembelajaran dengan maksimal sehingga interaksi guru dan siswa sangat terbatas yang memberikan dampak sebagian besar siswa cenderung pasif dalam proses pembelajaran. Penelitian ini bertujuan untuk memberikan alternative solusi pemecahan masalah dengan mengembangkan konsep pembelajaran berbasis teknologi informasi yaitu aplikasi e-learning pada mata pelajaran simulasi digital sehingga siswa memiliki peluang belajar lebih setelah mendapatkan materi dikelas, aplikasi dirancang guna mendukung proses pembelajaran secara konvensional. Hasil penelitian ini dapat disimpulkan bahwa Aplikasi E-Learning berbasis Website ini dapat membatu guru dalam malakukan interaksi lebih aktif dengan siswa tanpa harus dibatasi oleh ruang dan waktu meskipun diluar jam mata pelajaran dan guru dapat memantau proses evaluasi yang diberikan melaui media E-Learning.
\end{abstract}

\section{ABSTRACT}

Digital Simulation Subject is one of the subjects studied at SMK Negeri 3 Gorontalo in the 2013 curriculum. Digital Simulation is a subject in the TKJ major, Modeling Design and Building Information and the Construction and Property Business Department [1]. In this study, it was formulated that the problem that occurred was that limited time made it difficult for teachers to deliver and carry out learning optimally so that teacher and student interactions were very limited which had an impact that most students tended to be passive in the learning process. This study aims to provide alternative problem solving solutions by developing information technology-based learning concepts, namely e-learning applications on digital simulation subjects so that students have more learning opportunities after getting material in class, applications are designed to support the conventional learning process. The results of this study can be concluded that this Webistebased E-Learning Application can help teachers in interacting more actively with students without having to be limited by space and time even though outside class hours and teachers can monitor the evaluation process provided through E-Learning media.

Penulis Korespondensi:

Jojo,

Program Studi Informatika,

Universitas Komputer Indonesia, 
Email: jojo@gmail.com

\section{PENDAHULUAN}

Perkembangan Teknologi Informasi dewasa ini semakin pesat, suatu konsep dan mekanisme pendidikan berbasis Teknologi Informasi menjadi kebutuhan setiap sarana pendidikan termasuk sekolah[2]. Konsep yang kemudian terkenal dengan sebutan e-Learning ini membawa pengaruh terjadinya proses transformasi pendidikan konvensional ke dalam bentuk digital, baik secara konten dan sistemnya[3]. Salah satu sekolah negeri yang merupakan yang telah menerapkan konsep belajar mengajar berbasis teknologi informasi adalh SMKN 3 Gorontalo. Sekolah ini memiliki fasilitas pembelajaran dan sarana pendidikan yang cukup lengkap seperti laboratorium komputer dan tersedianya koneksi internet.

Mata Pelajaran Simulasi Digital sebagai salah satu mata pelajaran yang dipelajari di SMK Negeri 3 Gorontalo pada kurikulum 2013. Simulasi Digital merupakan Mata Pelajaran pada jurusan TKJ, Desain Permodelan dan Informasi Bnagunan dan dan Jurusan Bisnis Konstruksi dan Properti[4]. Jumlah guru yang mengajar mata pelajaran Simulasi Digital sebanyak 7 orang sedangkan jumlah siswa TKJ sebanyak 35 siswa, Dpib 1 sejumlah 30 siswa, dpib2 sejumlah 26 siswa dan Bkp sejumlah 30 siswa. Simulasi Digital memiliki peran penting untuk meningkatkan keterampilan siswa dalam bidang teknologi, lebih jelasnya Simulasi Digital menekankan pada kemampuan dan memahami teknologi berupa komputer sebagai alat informasi dan komunikasi. Selain itu, secara konseptual mata pelajaran ini bermanfaat untuk memberikan pengetahuan tentang cara-cara pengoperasian berbagai aplikasi dalam era serba digital [5].

Dalam pelaksanaan pembelajara simulasi terdapat kendala terkait dengan ruang, waktu, sumber belajar, dan pisikologi siswa. Terbatasnya waktu membuat guru sulit untuk menyampaikan dan melaksanakan pembelajaran dengan maksimal[6], Mata pelajaran simulasi digital sangat membutuhkan metode dan sumber belajar yang lain untuk mendukung proses pembelajaran, dengan memberikan pengalaman langsung kepada siswa dapat menghasilkan dampak yang baik terkait dengan pengalaman siswa dalam belajar[7] .

Berdasarkan hasil wawancara langsung kepada beberapa pihak sekolah baik guru maupun siswa, saat ini terdapat beberapa kendala dalam pembelajaran di SMKN 3 Gorontalo ini khususnya mata pelajaran simulasi digital, diantaranya masih adanya keterbatasan waktu di sekolah menjadi salah satu pemicu kurangnya pemberian materi yang dilakukan oleh pihak guru yang mengakibatkan siswa mengalami kesulitan untuk mendapatkat materi yang diajarkan. Selain itu, siswa memiliki kendala emosional dimana siswa malu bertanya disaat siswa tidak paham terhadap penyampaian materi yang diberikan guru sehingga dapat menimbulkan kurangnya interaksi antara guru dan siswa apalagi disaat guru berhalangan hadir yang dapat memperlambat kelancaran proses belajar mengajar.

Dalam penelitian terkait sebelumya yang telah dilakukan oleh peneliti [8],[9],dan [10],[11] bahwa dalam penelitian sebelumya terdapat permasalahan yang serupa dengan penelitian ini yakni proses pembelajaran saat ini masih bersifat kovensional, penggunaan sumber-sumber belajar belum difungsikan optimal dan siswa siswi masih belajar hanya bersumber pada guru. Sedangkan mata pelajaran Simulasi Digital membuthkan metode dan sumber belajar lain untuk mendukung pembelajaran.

Dari permasalahan tersebut, maka dalam penelitian ini di tetapkan suatu alternative sebagai solusi pemecahan masalah yaitu dengan pengembangan model pembelajaran menggunakan teknologi informasi berupa perancangan aplikasi e-learning pada mata pelajaran simulasi digital berbasis website[6], dengan adanya $e$-learning dapat membantu siswa dalam proses belajar yang dilakukan secara langsung maupun tidak langsung sehingga dapat meningkatkan hasil belajar siswa tanpa mengenyampikan kegiatan pembelajaran yang lain.

\section{METODE PENELITIAN}

\subsection{Metode Pengembangan Sistem}

Metode yang digunakan dalam pengembangan adalah metode research and development atau yang dikenal dengan metode penelitian dan pengembangan, metode ini didefinisikan sebagai metode penelitian yang digunakan untuk menghasilkan produk tertentu dan menguji keefektifan produk tersebut [12], Sejalan dengan hal tersebut, Sudaryono mendefinisikan penelitian dan pengembangan sebagai suatu proses pengumpulan dan analisis data dilakukan secara sistematis dan logis untuk mecapai tujuan tertentu [13]. 
JSAI : Journal Scientific and Applied Informatics

Vol. 4, No. 3, November 2021, hal. 280 285

E-ISSN: 2614-3054; P-ISSN: 2614-3062, Terakreditasi Kemenristekdikti, Sinta 5

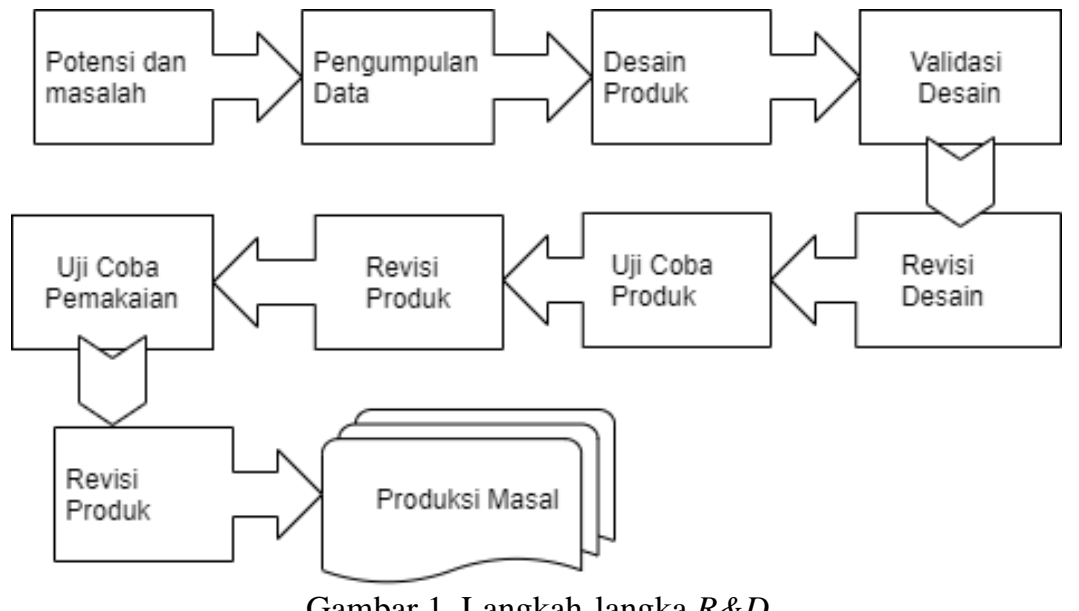

Metode Research and Development digunakan peneliti untuk mengembangkan atau membuat aplikasi $e$ learning mata pelajaran simulasi digital pada sekolah menengah kejuruan negeri 3 kota gorontalo.

\section{HASIL DAN ANALISIS}

\subsection{Sistem Yang Diusulkan}

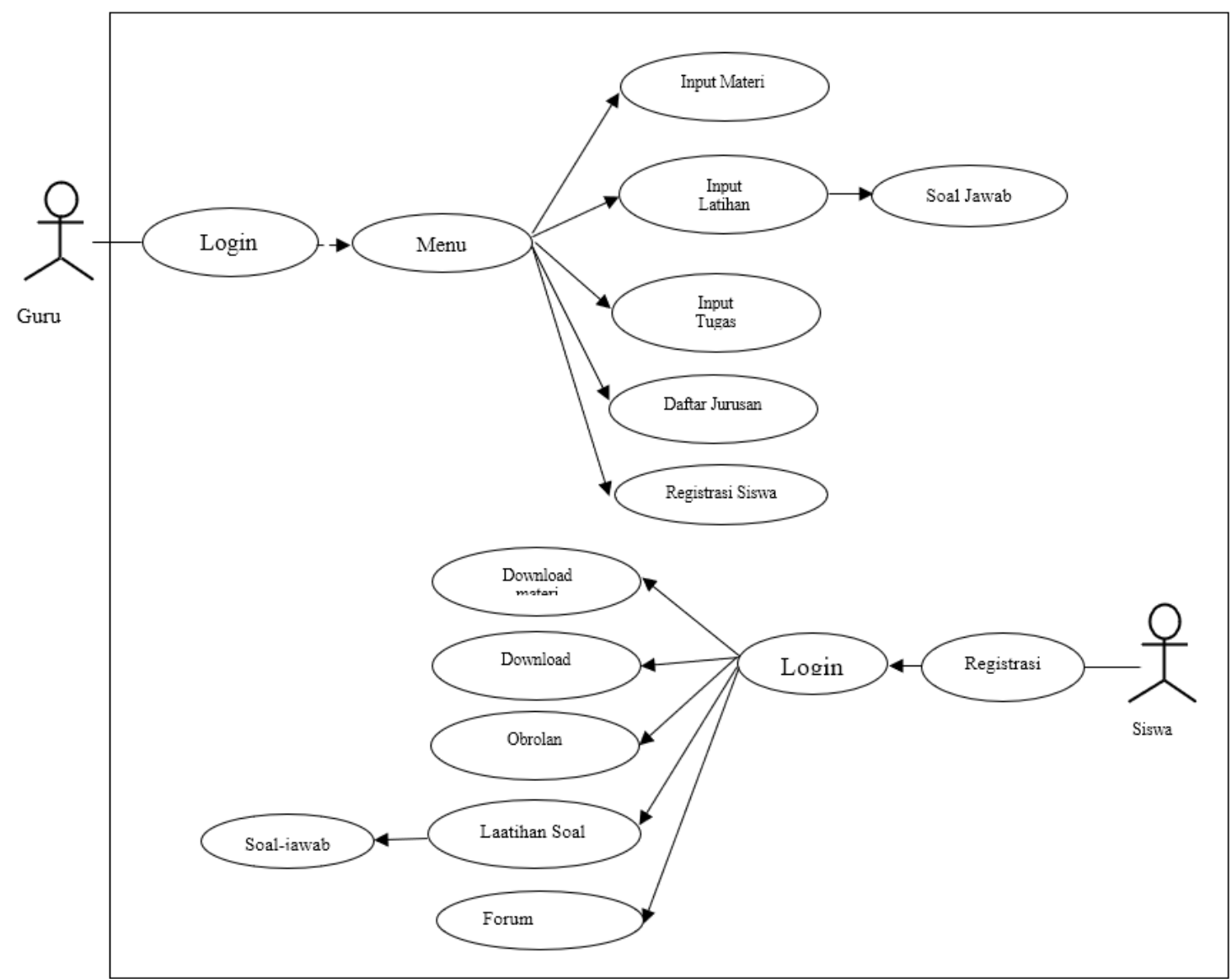

Gambar 2. Sistem Yang Diusulkan

Dari sistem yang diusulkan di atas kedua Aktor masih sama dengan system yang berjalan namun pada sistem yang diusulkan system berusaha mengatasi permasalahan yang ditemui pada sistem yang sedang berjalan khususnya untuk mendukung cara belajar konvensional dan memotivasi semangat belajar siswa dengan memberikan materi tambahan setelah jam mata pelajaran selesai dan dapat diakses langsung melalui media elektronik berbasis website.

Pada sistem yang diusulkan aktor Guru harus melakukan Login sebelum mengakses menu-menu yang tersedia dalam aplikasi, guru dapat melakukan pengisian materi atau bahan ajar, memberikan soal dan latihan tugas 
JSAI : Journal Scientific and Applied Informatics

Vol. 4, No. 3, November 2021, hal. 280 285

E-ISSN: 2614-3054; P-ISSN: 2614-3062, Terakreditasi Kemenristekdikti, Sinta 5

serta melakukan registrasi siswa yang dapat mengakses materi dan tugas yang diberikan Sedangkan actor siswa dapat langsung melihat materi yang diinput guru, latihan serta bahan evaluai dengan cara mengunduh melalui aplkasi e-learning yang dirancang.

\subsection{Rancangan Antar Muka}

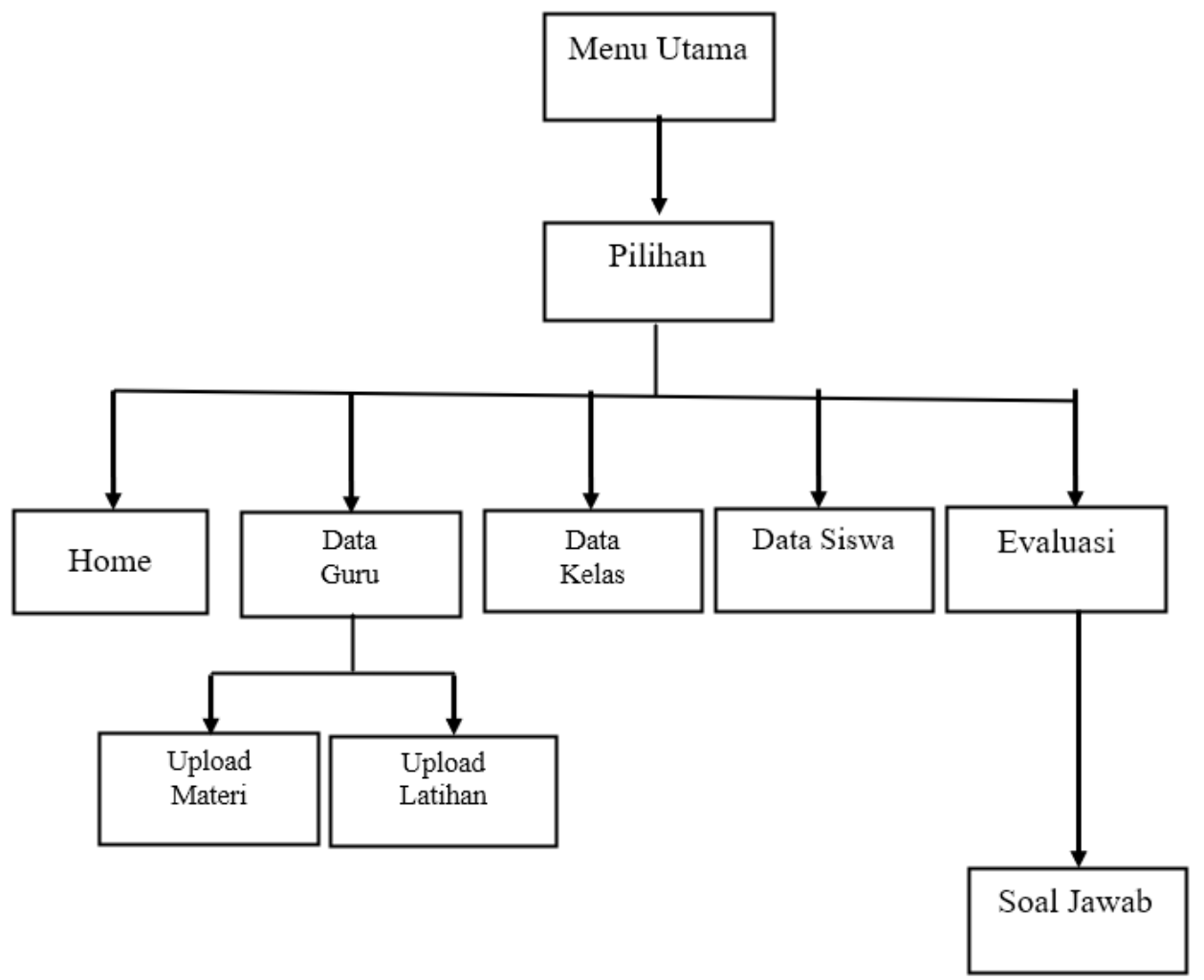

Gambar 3. Rancangan Antar Muka

Pada tahap ini rancangan antar muka dibuat berdasarkan kebutuhan siswa dan pengajar, antar muka dibangun untuk mempermudah pengguna aplikasi[14], dalam penelitian ini khususya untuk siswa agar supaya pengguna tidak kebingungan pada saat menggunakan aplikasi, antar muka dapat dilihat pada gambar dibawah ini :

\section{1.' Tampilan Home}

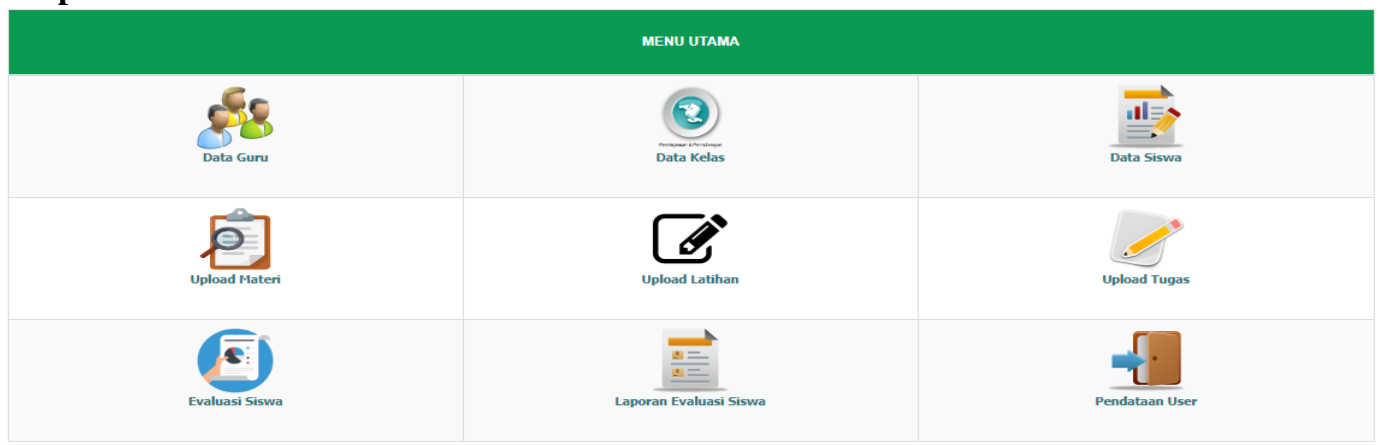

Gambar 4. Tampilan Home

Halaman ini menampilkan Menu- Menu yang dapat diakses oleh user admin dalam mengelola data untuk bahan pembelajaran simulasi digital berbasis e-learning.

\section{Halaman Pendataan Kelas}


JSAI : Journal Scientific and Applied Informatics

Vol. 4, No. 3, November 2021, hal. 280 285

E-ISSN: 2614-3054; P-ISSN: 2614-3062, Terakreditasi Kemenristekdikti, Sinta 5

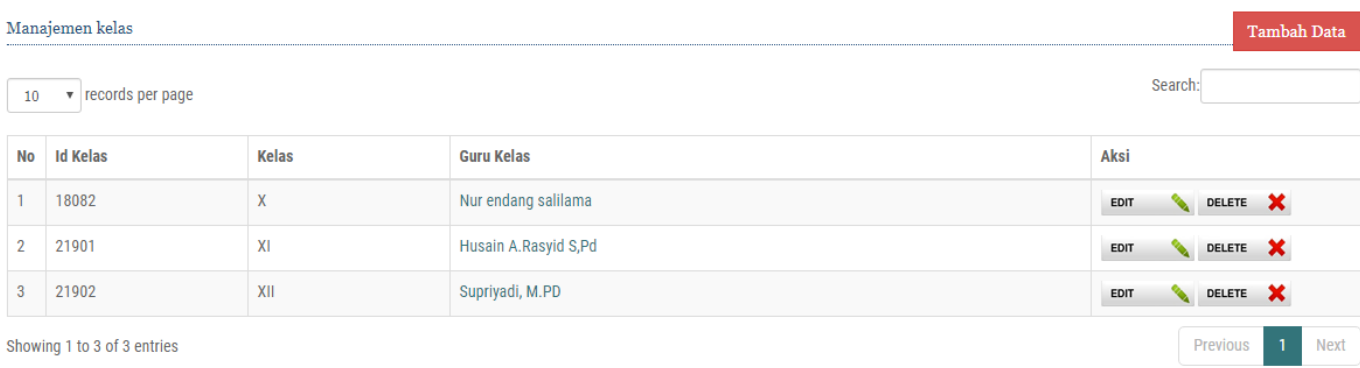

Gambar 5. Halaman Pendataan Kelas

Halaman di atas digunakan untuk mengisi Data Kelas dan Melihat daftar Kelas yang memiliki mata pelajaran Simulasi Digital untuk diajarkan.

\section{Halaman Pendataan Guru Kelas}

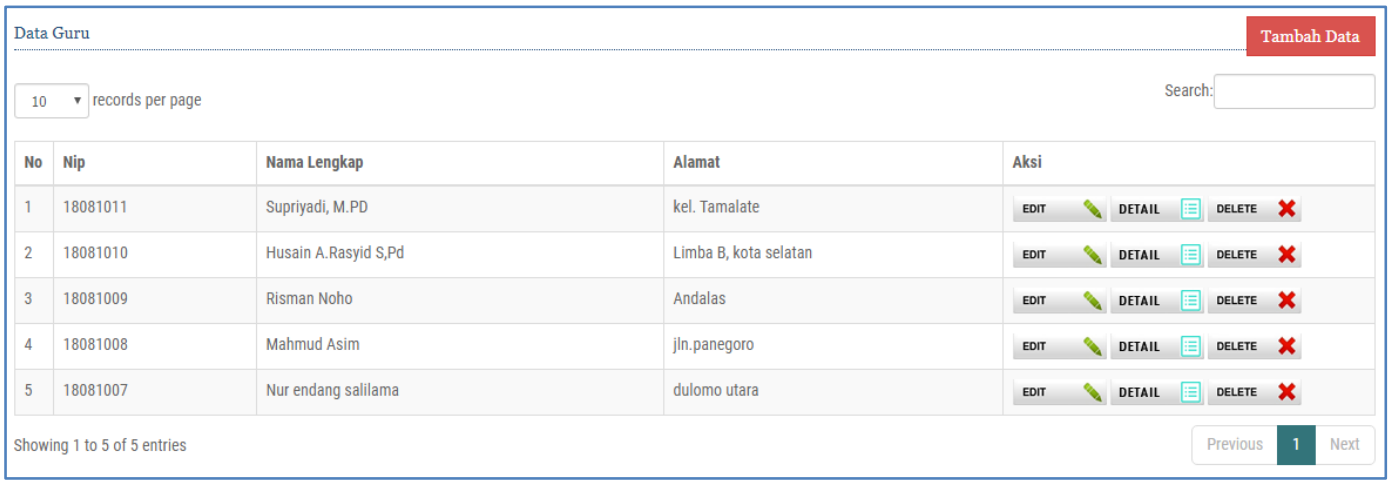

Gambar 6. Halaman Pendataan Kelas

Halaman di atas digunakan untuk menambahkan data Guru dan Melihat Daftar Guru Yang dapat mengajar Mata pelajaran Simulasi Digital.

\section{Halaman View Materi Pelajaran}

\begin{tabular}{|c|c|c|c|c|c|c|}
\hline \multicolumn{6}{|c|}{ Upload Data Materi } & \multirow[t]{2}{*}{ Tambah Data } \\
\hline \multicolumn{6}{|c|}{10 records per page } & \\
\hline No & Judul & Kelas & Nama File & Tgl Posting & Guru & Aksi \\
\hline 1 & $\begin{array}{l}\text { Materi kelas X Semester } 2 \text { Simulasi } \\
\text { Digital }\end{array}$ & $\mathrm{x}$ & $\begin{array}{l}\text { MATERI KELAS } \mathrm{X} \text { SEMESTER } 2 \\
\text { Simulasi Digital.docx }\end{array}$ & 24 Juli 2019 & Nur endang salilama & EDIT $\mid$ Delete $\boldsymbol{X}$ \\
\hline 2 & Materi kelas X Semester 1 & $\mathrm{x}$ & $\begin{array}{l}\text { MATERI KELAS X SEMESTER } 1 \\
\text { Simulasi Digital.docx }\end{array}$ & 24 Juli 2019 & Nur endang salilama & eotr \& DELete $\boldsymbol{x}$ \\
\hline show & ng 1 to 2 of 2 entries & & & & & \begin{tabular}{l|l|l} 
Previous & 1 & Next
\end{tabular} \\
\hline
\end{tabular}

Gambar 7. Halaman Pendataan Materi

Halaman Pendataan Mataeri Pelajaran yang dapat diakses oleh Guru Kelas untuk Melakukan Input Data MAteri berdasarkan judul, Kelas dan dapat langsung di kirimkan dalam bentuk pdf atau file doc sehingga siswa dapat dengan mudah memperoleh materi pelajaran melalui website.

\section{Metode Pegujia black box}

Metode pengujian black box mengfokuskan pada keperluan fungsional dari software. Oleh karena itu ujicoba black box memungkinkan pengembang software untuk membuat himpunan kondisi input yang akan melatih seluruh syarat-syarat fungsional suatu program apakah berjalan sesuai yang diharapkan atau sebaliknya[15].

Tabel 5. 1. Pengujian Black box

\begin{tabular}{|l|c|c|c|c|}
\hline No & Input/Event & Proses & $\begin{array}{c}\text { Output/Next } \\
\text { State }\end{array}$ & $\begin{array}{c}\text { Hasil } \\
\text { Pengujian }\end{array}$ \\
\hline
\end{tabular}


JSAI : Journal Scientific and Applied Informatics

Vol. 4, No. 3, November 2021, hal. 280 285

E-ISSN: 2614-3054; P-ISSN: 2614-3062, Terakreditasi Kemenristekdikti, Sinta 5

\begin{tabular}{|c|c|c|c|c|}
\hline 1. & $\begin{array}{l}\text { Jika tombol login } \\
\text { ditekan }\end{array}$ & $\begin{array}{l}\text { System mengarahkan masuk ke } \\
\text { tampilan menu }\end{array}$ & Tampilkan menu & Sesuai \\
\hline 2. & $\begin{array}{l}\text { Jika menu Data } \\
\text { Siswa }\end{array}$ & $\begin{array}{l}\text { System mengarahkan user untuk melihat Data } \\
\text { detail biodata siswa }\end{array}$ & $\begin{array}{l}\text { Tampilkan } \\
\text { Biodata Siswa }\end{array}$ & Sesuai \\
\hline 3. & Jika Menu Materi & $\begin{array}{l}\text { System menampikan daftar Materi yang telah } \\
\text { di input dan memanggil dari database system. }\end{array}$ & $\begin{array}{l}\text { Tampilkan daftar } \\
\text { materi }\end{array}$ & Sesuai \\
\hline 4. & $\begin{array}{l}\text { Jika Menu } \\
\text { Evaluasi }\end{array}$ & $\begin{array}{l}\text { System menampilkan data soal evaluasi yang } \\
\text { telah didaftarkan melalui inputan admin. }\end{array}$ & $\begin{array}{l}\text { Tampilkan data } \\
\text { Evaluasi }\end{array}$ & Sesuai \\
\hline 5 & $\begin{array}{l}\text { Jika menu logout } \\
\text { ditekan }\end{array}$ & $\begin{array}{l}\text { User akan diarahkan unutk keluar } \\
\text { dari system }\end{array}$ & $\begin{array}{l}\text { Keluar dari akun } \\
\text { yang aktif }\end{array}$ & Sesuai \\
\hline
\end{tabular}

\section{KESIMPULAN}

Dari hasil penelitian yang dilakukan pada pengembangan pembelajaran Mata Pelajaran Simulasi Digital Berbasis E-Learning tersebut maka penulis menarik kesimpulan yaitu aplikasi E-Learning berbasis Webiste ini dapat membatu guru dalam malakukan interaksi lebih aktif dengan siswa tanpa harus dibatasi oleh ruang dan waktu meskipun diluar jam mata pelajaran dan guru dapat memantau proses evaluasi yang diberikan melalui media E-Learning.

\section{REFERENSI}

[1] Profile Sekolah Menengah Kejuruan Negeri 3 Gorontalo, "No Title," Gorontalo, 2018.

[2] N. L. Nathaniel D Oye, Mazleena Salleh, "Challenges Of E-Learning In nigerian University Education based On The Experience Of Developed Countries," Interational J. Manag. Inf. Technol., vol. 3, pp. 39-48, 2011.

[3] I. M. G. Sunarya and I. M. Putrama, "PENGEMBANGAN E-MODUL BERBASIS PROJECT BASED LEARNING PADA MATA PELAJARAN SIMULASI DIGITAL UNTUK SISWA KELAS X STUDI KASUS DI SMK NEGERI 2 SINGARAJA,” vol. 13, no. 2, pp. 184-197, 2016.

[4] P. A. E. Mata, P. Fisika, K. Ipa, and D. I. Sman, "Jurnal Teknologi Jurnal Teknologi," vol. 8, no. 2, pp. 55-62, 2018.

[5] P. Karakter and D. I. Smk, "PENGEMBANGAN LABORATORIUM VIRTUAL UNTUK VIRTUAL LABORATORY DEVELOPMENT FOR PRACTICUM AND FACILITATING CHARACTER EDUCATION IN VOCATIONAL HIGH," pp. 81-90.

[6] C. V. Andreea Maria T, "Education 2.0 E-Learning Method," in Procedia Social And behavioral Sciences, 2015, pp. 376-380.

[7] V. D. Soni, "IOT Connected with e-Learning," Int. J. Integr. Educ., vol. 2, pp. 273-277, 2019.

[8] Z. Cyly, A. Dalu, and M. Rohman, "Pengembangan E-Learning Sebagai Media Pembelajaran Simulasi dan Komunikasi Digital bagi Siswa SMK," vol. 04, pp. 25-33, 2019.

[9] D. I. Smk and N. Kubutambahan, "PENGEMBANGAN KONTEN E-LEARNING SIMULASI DIGITAL BERBASIS PROYEK UNTUK SISWA KELAS X," vol. 9, no. 1, 2019.

[10] A. S. Rajapandian Radha, K Mahalakshmi, V Sathish Kumar, "E-Learning Durig Lockdow of covid 19 pamdemic : A gloal Perspective," Int. J. Control Autom., vol. 13, pp. 1089-1099, 2020.

[11] A. E. Putri, E. Edidas, and I. P. Dewi, "Pengaruh Model Active Learning Tipe Practice Rehearsal Pairs Terhadap Hasil Belajar Siswa X Tkj Dalam Mata Pelajaran Simulasi Digital Di Smk Negeri 3 Pariaman," Voteteknika (Vocational Tek. Elektron. dan Inform., vol. 6, no. 1, 2018.

[12] Prof. Dr. Sugiyono, Metode Penelitian dan pengembangan "research and development, Ke-4. Bandung: Alfabeta, 2019.

[13] A. S. Rosa and Salahuddi M, Rekayasa Perangkat Lunak, Ketiga. Bandung: Informatika, 2013.

[14] S. . Pressman, Rekayasa Perangkat Lunak (Pendekatan Praktis), Edisi 7. Jakarta: Gramedia Jakarta, 2015.

[15] B. Pang and L. Lee, "Opinion Mining and Sentiment Analysis," Foundations and Trends® in Information Retrieval, vol. 2, no. 1-2. pp. 1-135, 2008. 